\title{
MODELO DE MONITORAMENTO DE GESTÃO AMBIENTAL PRA AS INDÚSTRIAS DE ROCHAS ORNAMENTAIS
}

\author{
E. M. Sales ${ }^{1}$, J. C. M. dos $\operatorname{Santos}^{1}$ A. B. da $\operatorname{Costa}^{1}$ V. N. F. Lisboa ${ }^{1}$ e A. M de Medeiros ${ }^{2}$ \\ ${ }^{1}$ Universidade Federal de Campina Grande, Departamento de Engenharia \\ ${ }^{2}$ Universidade Estadual da Paraíba, Departamento de Química Industrial \\ E-mail para contato: emanuele.montenegro@gmail.com
}

\begin{abstract}
RESUMO - As indústrias de rochas ornamentais, grandes fontes produtivas no setor de granitos, apresentam em média o consumo de água em torno de $10.000 \mathrm{~L} / \mathrm{d}$ e geram aproximadamente 48.000 toneladas de resíduos sólidos por ano. A gestão inadequada de resíduos constitui crime ambiental e pode acarretar multas. O crescimento industrial agrava ainda mais essa problemática ambiental que não deve e nem pode ser esquecida. Diante do exposto o setor tem o desafio de conciliar o desenvolvimento industrial e o desenvolvimento sustentável. Dentro dessa linha a presente pesquisa aborda uma revisão bibliográfica referente à indústria supracitada e como resultado apresenta um modelo de monitoramento de gestão ambiental para a mesma, onde as boas práticas de redução na fonte geradora, substituição da matéria-prima, reutilização e reciclagem são alternativas rentáveis.
\end{abstract}

\section{INTRODUÇÃO}

A Associação Brasileira de Normas Técnicas (ABNT) define rocha ornamental como uma substância rochosa natural que, submetida a diferentes graus de modelamento ou beneficiamento, pode ser utilizada como uma função estética qualquer. As rochas ornamentais são utilizadas na indústria da construção civil como revestimentos internos e externos de paredes, pisos, pilares, colunas e soleiras. Compõem também peças isoladas, como estruturas, tampos, pés de mesa, bancadas, balcões, lápides e arte funerária em geral, além de edificações (PEITER \& CHIODI FILHO, 2001).

Estima-se que o setor de rochas movimente transações comerciais de US\$ 80-100 bilhões/ano. A produção mundial noticiada evoluiu de 1,8 milhão toneladas/ano, na década de 20, para um patamar atual de 100 milhões toneladas/ano. Cerca de 46 milhões toneladas de rochas brutas e beneficiadas foram comercializadas no mercado internacional em 2007. Prevê-se que no ano de 2025 a produção mundial ultrapassará 400 milhões toneladas, correspondentes a quase 5 bilhões $\mathrm{m}^{2}$ equivalentes/ano, devendo-se multiplicar por cinco o volume físico das atuais transações internacionais (NERY; SILVA, 2001; MONTANI, 2003, MELLO, 2004). 


\section{9 a 22 de outubro de 2014 \\ Florianópolis/SC}

A adequada disposição e o aproveitamento dos rejeitos da lavra e do beneficiamento constituem um dos problemas mais agudos do setor de rochas. O aproveitamento desses rejeitos pode ser canalizado para a produção de chapas aglomeradas ou prensadas, bem como para matérias-primas de uso indústria. Nesse sentido, o presente trabalho insere-se nos estudos referentes a engenharia ambiental tendo como objeto de estudo a poluição causada por compostos odorantes e toda a problemática referente a odores.

\section{METODOLOGIA}

A metodologia consistiu na realização das atividades de revisão bibliográfica feita mediante referências nacionais e internacionais sobre os temas: Rochas ornamentais, geração e a problemática ambiental do processo de lavra de rochas ornamentais e seus beneficiamento.

\section{REVISÃO BIBLIOGRÁFICA}

\subsection{Rochas}

Comercialmente, as rochas ornamentais são definidas essencialmente em duas principais categorias, que são os "granitos" e os "mármores", distinguidas com base na sua composição mineralógica. Os granitos abrangeriam as rochas silicatadas, ou seja, formadas por minerais estruturalmente constituídos por tetraedros de $\mathrm{SiO}_{4}$, ao passo que os mármores incluiriam as rochas composicionalmente carbonáticas. Segundo Vidal (2002), estas duas categorias de rochas respondem largamente pelas variedades de rochas ornamentais e de revestimento comercializadas, representando cerca de $80 \%$ da produção mundial. No Brasil, dados da ABIROCHAS/CETEM (2002) indicam que os "granitos" correspondem a 57\% da produção nacional de rochas ornamentais, enquanto apenas 19\% são relativos aos "mármores". As demais categorias, não menos importantes, correspondem os quartzitos, as ardósias, os serpentinitos, os esteatitos, os arenitos e os conglomerados.

Segundo Chiodi 2009, na categoria de rocha carbonática, metamorfizada, o mármore tem quase a mesma aplicabilidade que o granito. A seu favor está a durabilidade e a nobreza, e seu ponto fraco é ser menos resistente a riscos (como arranhões) e mais sensível ao ataque químico, como os produtos de limpeza (ácido). Por força da constituição de seus terrenos geológicos, os mármores dos países mediterrâneos são mais nobres, possuem massa fina e padrões cromáticos variados, de acordo com Chiodi 2009.

\subsubsection{Granito}

O conceito comercial de granito é muito genérico, abrangendo em sua essência as rochas composicionalmente silicatadas, com mineralogia principal definida a base de feldspatos, feldspatóides e quartzo, ou seja, minerais com dureza Mohs entre 6 e 7. Dependendo da variedade, pode incluir acessoriamente expressivo conteúdo de minerais máficos (escuros) notadamente biotita, anfibólios e piroxênios. É importante complementar, que os feldspatóides são constituintes característicos de rochas geologicamente classificadas como alcalinas que também primam geralmente pela ausência de quartzo (PEITER \& CHIODI FILHO, 2001). 


\section{9 a 22 de outubro de 2014 \\ Florianópolis/SC}

Do ponto de vista da geologia, "granito comercial" inclui tanto rochas ígneas quanto metamórficas, abrangendo, neste sentido, uma variada gama de tipos textural, estrutural e composicionalmente distintos, o que reflete em cores e padrões estéticos diversos. Dentre as rochas ígneas, os tipos mais comuns encontrados naturalmente e utilizados como rocha ornamental e de revestimento são os granitos sensu strictu, os quartzomonzonitos, os granodioritos e os quartzodioritos. Constituem variedades plutônicas basicamente quartzo-feldspáticas, fanerocristalinas, com mineralogia acessória representada principalmente por micas (biotita e muscovita) e anfibólios (hornblenda), em proporções variáveis. Apresentam granulação fina a grossa, porfirítica ou não, podendo exibir uma fraca anisotropia, dada por alinhamento mineral.

\subsubsection{Mármores}

Os mármores, no sentido comercial, incluem rochas composicionalmente carbonáticas, sedimentares e metamórficas. Podem ser maciços a bandeados, cripto a microcristalinos, até granoblásticos médios a grossos nos tipos metamórficos, com minerais predominantemente de dureza Mohs entre 3 e 4, e tons de cores variando do creme-esbranquiçado ao bege-amarelado, entre outros. A mineralogia predominante consiste de calcita $\left(\mathrm{CaCO}_{3}\right)$ e dolomita $\mathrm{CaMg}\left(\mathrm{CO}_{3}\right)_{2}$, em geral com o predomínio da primeira. Acessoriamente, pode incluir quartzo, pirita, siderita, feldspatos, entre outros, além de impurezas, tais como argilas, os quais definem seu padrão cromático, visto que a calcita e a dolomita são brancas. (ABREU \& CARVALHO, 1994; SANTOS \& CHIODI FILHO, 1991).

Os mármores, pela sua própria natureza, são rochas macias, pouco abrasivas, e de baixa resistência aos agentes intempéricos. Aceitam com relativa facilidade os processos de desdobramento. As variedades recristalizadas têm a vantagem de um menor índice de porosidade e de absorção de água.

\subsection{Lavra das Rochas}

A partir do momento em que se atinja um certo grau de conhecimento da reserva no que diz respeito à forma e volume disponíveis, qualidade do material, dimensões do bloco a serem lavrados, características geológicas e petrogáficas, pode-se passar ao estudo de planejamento de lavra da pedreira adotando-se uma metodologia de extração e recuperação ambiental (CARANASSIOS 7 CICCU. 1992).

A lavra por desabamento consiste no desmonte da rocha por explosivos, gerando grande quantidade de material fragmentado, bem como grandes blocos de forma irregular. Com o desenvolvimento de novas técnicas de corte e a preocupação crescente com valores ambientais, tal tecnologia vem sendo abandonada, restringindo-se apenas a casos em que haja condições extremamente favoráveis, tais como abundância de reservas, topografia acidentada e grandes áreas disponíveis para deposição do material estéril e material de baixo (ou limitado) valor comercial.

A Lavra por bancadas é um método conduzido através de bancadas, cuja altura pode variar de baixa (altura igual a uma das dimensões do bloco comercializável) a alta (quando igual a um número 
múltiplo de uma das dimensões do bloco).

A lavra de matacões são porções definidas de um maciço rochoso, individualizada pela atuação interpérica nas fraturas e destacadas por erosão. São peculiares as rochas silicatadas (granito) e apresentam morfologia geralmente arredondada, resultado da esfoliação esferoidal (acebolamento).

No caso de extração em maciços rochosos, podem-se aproveitar rochas isoladas na área da pedreira (lavra por matacão), ou detonando a base de um maciço e removendo-se os blocos aproveitáveis (lavra por desabamento). Mas o método de extração em blocos mais aplicado é removendo-se os blocos da frente de lavra através de técnicas de corte contínuo ou em costura (lavra por maciços rochosos) (CABELLO et al ,2012).

A lavra por maciços rochosos é de longe a mais usada. A extração por maciços rochosos pode ser executada em cotas acima ou abaixo do nível do terreno. Para superfícies horizontais ou subhorizontais, características de planícies ou de platôs elevados, a extração dá-se em cota inferior à cota natural do terreno, após a retirada do estéril. A frente de lavra será, então, do tipo fossa ou do tipo poço (Cabello, 2011).

A escolha da tecnologia de corte a ser empregada nas atividades de lavra dar-se-á de fatores tais como: tipo de rocha, suas características petrográficas e estruturais, valor do material no mercado, meio-ambiente, disponibilidade financeira da empresa, dentre outros (PINHEIRO, 1995).

Nos últimos anos, as tecnologias de corte, tradicionais ou avançadas, têm experimentado um considerável progresso, decorrente do aumento da demanda por rochas para uso na engenharia de construções, obras de arte e decoração de interiores.

As técnicas atualmente mais avançadas são as seguintes:

- Corte por fio diamantado

- Waterjet

- Correia diamantada

\subsection{Impactos Ambientais}

A geração de resíduos é inerente a qualquer processo de trans-formação de materiais ou produção. $\mathrm{O}$ processo de benefciamento de rocha ornamental não é diferente - seus resíduos geram impacto ambiental em várias etapas do processo produtivo, como as lamas do processo de desdobramento e polimento, os casqueiros e cacos e outros resíduos como lâminas e granalhas desgastadas, sacos de cimento e de cal, restos de pastilhas abrasivas, entre outros (NEVES et al., 1999; LIMA FILHO et al., 2000).

Como toda atividade de mineração a extração dos blocos de uma lavra de rochas ornamentais é 
uma atividade altamente impactante. Primeiramente se faz necessário o desmatamento e a remoção do solo para tornar viável o acesso e a operação da lavra, o que provoca um efeito negativo na fauna e flora, além do impacto visual.

Observa-se em seguida um intenso movimento de máquinas, carros e caminhões acompanhados de ruídos e poeira, agravando-se quando a lavra entra em operação com as vibrações provocadas pelas explosões e máquinas perfuratrizes, além dos cascalhos de pedras (GIACONI, 1998).

$\mathrm{Na}$ etapa de desdobramento, os resíduos comumente gerados são, os restos e fragmentos de rochas, conhecido como casqueiros, o plástico, papel e papelão, oriundo das embalagens dos insumos utilizados, óleo e graxa decorrente da manutenção dos teares, metálico, oriundo das lâminas gastas e peças substituídas, e o mais volumoso de todos, a lama abrasiva (CALMON et al., 1997).

Na etapa de polimento de chapas, vemos como resíduos comumente gerados os fragmentos de rocha, papel, plástico e papelão, também decorrente da embalagem dos insumos utilizados, os restos de abrasivos gastos no polimento e a exemplo da etapa de desdobramento, a lama abrasiva, porém, esta é gerada a partir da decantação da água utilizada no polimento, quando da limpeza dos tanques de decantação (NEVES et al., 1999; LIMA FILHO et al., 2000; CALMON et al., 1997).

Outro problema observado nas empresas é durante os serviços de manutenção dos equipamentos, pois não há uma preocupação por parte dos funcionários em evitar que graxas e lubrificantes respinguem na área de trabalho, sendo carreados para a lama alterando sua composição.

Por esses motivos a correta gestão da atividade operacional, e matéria-prima, assim como estudos acerca dos impactos ambientais gerados e o levantamento de soluções para os mesmo é de grande importância para preservação dos recursos naturais do planeta.

\section{CONCLUSÃO}

Este trabalho objetivou fazer um breve referencial teórico a cerca da problemática ambiental causada pelas indústrias de extração e comércio de rochas ambientais. Após o exposto pode-se perceber que a extração de rochas ornamentais causa poluição das águas, poluição sonora e poluição dos solos. Dessa forma, um rígido controle de gestão ambiental é indispensável para sanar tais problemas.

\section{REFERÊNCIAS}

ABIROCHAS/CETEM. 2002. Catálogo de rochas ornamentais do Brasil. Rio de Janeiro. CDROM. Windows 95.

ABNT - Associação Brasileira de Normas Técnicas. 1995. Catálogo ABNT. Rio de Janeiro. $360 \mathrm{p}$.

ABREU, A., CARVALHO, D. A forças das pedras: O mármore e granito no Espírito Santo. Vitória, ES: Pedreiras do Brasil, 89p. 1994. 


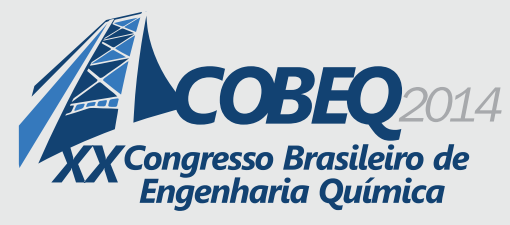

\section{9 a 22 de outubro de 2014 \\ Florianópolis/SC}

CABELLO, M. L. R., Reciclagem de resíduo gerado na extração de quartzito. Tese de doutorado (Programa de Pós-Graduação em Engenharia Metalúrgica, Materiais e de Minas). Universidade Federal de Minas Gerais, Belo Horizonte. 172p, 2011.

CALMON, J.L. et al. Aproveitamento do resíduo do corte de granito para produção de argamassas de assentamento. In: II Simpósio Brasileiro de Tecnologia das argamassas, Anais. Salvador, BA: ANTAC, 1997, p. 64-75.

CARANASSIOS, A., CICCU, R. Tecnologia de estração e valorização das rochas ornamentais. Rochas de Qualidade, São Paulo, n.109, p.58-77, abr. - jun. 1992.

CHIODI FILHO, C.; RODRIGUES, E. de P. Guia de Aplicação de Rochas em Revestimentos; Projeto Bula. São Paulo: Abirochas, 2009. 100 p.

GIACONI, W.J. Perfil atual da indústria de rochas ornamentais no município de Cachoeiro de Itapemirim (ES). Campinas, SP, 1998. 85 p. Dissertação de Mestrado na Área de Administração e Políticas de Recursos Minerais.

LIMA FILHO, V.X., et al. Estudo da viabilidade técnica da substituição dos pós cerâmicos convencionais por pó de granito na injeção de peças cerâmicas á baixa pressão. In: Congresso Nacional de Engenharia Mecânica. Anais. Nov/200, Natal/RN, (b).

MELLO, Ivan Sergio de Cavalcanti. Indicadores do Mercado Nacional e Internacional de rochas Ornamentais e para Revestimento. A Cadeia produtiva de rochas ornamentais e para revestimento no Estado de São Paulo: diretrizes e ações para inovação e competitividade. MELLO, Ivan Sergio de Cavalcanti (organizador). São Paulo: Instituto de Pesquisas Tecnológicas, 2004, p.1-26.

M. L. R. Cabello${ }^{1}$, A. E. C. Peres, A. H. Martins, R. G. O. Silva e C. A. Pereira.Métodos de Lavra Aplicada à Extração de Rochas Ornamentais, HOLOS, Ano 28, Vol 5, 2012.

MONTANI, C. Stone 2000 - World Marketing Handbook. Faenza (ITA): Gruppo Editoriale Faenza Editrice, 2000, 213 p.

NERY, Miguel Antonio Cedraz; SILVA, Emanoel Apolinário da. Balanço mineral de rochas ornamentais 1988-2000. [S.1.], 2001. Mimeografado.

NEVES, G., et al. Utilização de resíduos da serragem de granitos para confecção de tijolos cerâmicos. In: 43 Congresso Brasileiro de Cerâmica. Anais. Florianópolis/SC. Jun/1999.

PEITER, C. C.; CHIODI FILHO, C. Rochas Ornamentais no Século XXI: Bases para um Política de Desenvolvimento Sustentado das Exportações Brasileiras. Rio de Janeiro: CETEM/ABIROCHAS, 2001. 160 p.

PINHEIRO, J. R. Metodologias e tecnologias de extração de rochas ornamentais. Vitória: SENAI/ES, DAE, 1995. 44P.

SANTOS, J.F., CHIODI FILHO. C. Programa Michelangelo Espírito Santo: uma proposta para liderança nacional em rochas ornamentais. Brasília. D.N.P.M., 1991. 45 p (apost,).

Vidal, F. W. H. Avaliação de granitos ornamentais do nordeste através de suas características tecnológicas. In: III Simpósio sobre Rochas Ornamentais do Nordeste, Anais, Recife, PE, 2002. 